\title{
Thirty years of coral heat-stress experiments: a review of methods
}

\author{
Rowan H. McLachlan ${ }^{1} \cdot$ James T. Price $^{1} \cdot$ Sarah L. Solomon $^{1} \cdot$ Andréa G. Grottoli $^{1}$
}

Received: 16 December 2019/ Accepted: 1 April 2020

(C) The Author(s) 2020

\begin{abstract}
For over three decades, scientists have conducted heat-stress experiments to predict how coral will respond to ocean warming due to global climate change. However, there are often conflicting results in the literature that are difficult to resolve, which we hypothesize are a result of unintended biases, variation in experimental design, and underreporting of critical methodological information. Here, we reviewed 255 coral heat-stress experiments to (1) document where and when they were conducted and on which species, (2) assess variability in experimental design, and (3) quantify the diversity of response variables measured. First, we found that twothirds of studies were conducted in only three countries, three coral species were more heavily studied than others, and only $4 \%$ of studies focused on earlier life stages. Second, slightly more than half of all heat-stress exposures were less than $8 \mathrm{~d}$ in duration, only $17 \%$ of experiments fed corals, and experimental conditions varied widely, including the level and rate of temperature increase, light intensity, number of genets used, and the length of acclimation period. In addition, $95 \%, 55 \%$, and $>35 \%$ of studies did not report tank flow conditions, light-dark cycle used, or
\end{abstract}

Topic Editor Morgan S. Pratchett

Electronic supplementary material The online version of this article (https://doi.org/10.1007/s00338-020-01931-9) contains supplementary material, which is available to authorized users.

Rowan H. McLachlan

mclachlan.8@osu.edu

$\triangle$ Andréa G. Grottoli

grottoli.1@osu.edu

1 School of Earth Sciences, The Ohio State University, Columbus, OH 43210, USA the date of the experiment, respectively. Finally, we found that $21 \%$ of experiments did not measure any bleaching phenotype traits, $77 \%$ did not identify the Symbiodiniaceae endosymbiont, and the contribution of the coral host in the physiological response to heat-stress was often not investigated. This review highlights geographic, taxonomic, and heat-stress duration biases in our understanding of coral bleaching, and large variability in the reporting and design of heat-stress experiments that could account for some of the discrepancies in the literature. Development of some best practice recommendations for coral bleaching experiments could improve cross-studies comparisons and increase the efficiency of coral bleaching research at a time when it is needed most.

Keywords Coral bleaching - Coral heat-stress . Temperature experiment · Heat-stress experiment . Bleaching experiment $\cdot$ Coral bleaching review

\section{Introduction}

Increasing atmospheric carbon dioxide concentrations are driving increases in seawater temperatures and causing ocean acidification, both of which threaten the survival of coral reef ecosystems (e.g., Veron et al. 2009; Cantin et al. 2010; Frieler et al. 2013; Hughes et al. 2018a; Eakin et al. 2019). Increasing seawater temperatures (i.e., ocean warming) is stressful for corals, and this heat stress causes a breakdown of the symbiosis between the coral host and its endosymbiotic dinoflagellate (i.e., Symbiodiniaceae), leading to coral bleaching (Jokiel and Coles 1990; Glynn 1996; Brown 1997; Hoegh-Guldberg 1999). In this bleached state, corals suffer reduced growth, health, and reproductive output leaving them more susceptible to 
disease and mortality (e.g., Buddemeier et al. 2004; Brown 1997; Hoegh-Guldberg 1999; Maynard et al. 2015; Omori et al. 2001). Vast areas of reef habitat have already suffered substantial mortality following mass bleaching events in recent years. For example, $16 \%$ mortality was observed globally in 1998 (Wilkinson 2000; Veron et al. 2009) and $67 \%$ mortality was observed in the northern Great Barrier Reef in 2016 (Hughes et al. 2018b). Furthermore, during 2014-2017 many reefs experienced back-to-back bleaching events for the first time on record (Eakin et al. 2019; Harrison et al. 2019; Head et al. 2019; Hughes et al. 2019). Overall, the frequency, intensity, and duration of heatstress events have increased over the last 35 years (Eakin et al. 2009; Hughes et al. 2018a; Eakin et al. 2019), and this trend is expected to continue as tropical seawater temperatures rise by another $1-3{ }^{\circ} \mathrm{C}$ (IPCC 2013) or more (Hughes et al. 2017). Severe bleaching is predicted to occur annually by 2030 in some regions, and globally by 2055 (van Hooidonk et al. 2014). Given the severity of projected global warming trends, we need to increase our understanding of the coral bleaching mechanisms and the factors that determine tolerance and resilience to rising seawater temperatures.

Technological advances over the last three decades have provided scientists new tools with which to research coral bleaching mechanisms using controlled heat-stress experiments (see review by Cziesielski et al. 2019). However, a common thread found throughout such studies is that the response of corals to elevated temperature varies among species, populations, and among genetically distinct individuals (e.g., Loya et al. 2001; Grottoli et al. 2006; Palumbi et al. 2014; Muller et al. 2018). Yet, some of the reported variability could be a function of unintended biases, variation in the experimental design, or the underreporting of critical information that would facilitate comparisons among studies. The aim of this review is to quantify the methodological variability and underreporting in the literature, we reviewed the experiments and reporting criteria of 243 peer-reviewed journal articles published since 1992 . We approach this review with three specific goals:

Goal 1 To document the timing and location of heatstress studies, and the taxonomy of the corals studied.

Compiling this information will improve our understanding of where most experimental-heat-stress research has originated from, both spatially and temporally, and identify potential biases regarding which coral species have been most heavily studied.

Goal 2 To quantify the variability in coral heat-stress experimental design methods.

It is unclear how much of the observed variability in coral heat-stress responses can be attributed to differences in experimental design. For example, there is evidence that bleaching resistance varies depending upon the rate of temperature increase, with differences in the ramp rate of as little as $0.5^{\circ} \mathrm{C} \mathrm{d}^{-1}$ being shown to cause differential responses (Middlebrook et al. 2010). In addition, there are several environmental variables known to influence the response of corals to heat stress, such as light (e.g., Jokiel and Coles 1977; Reynaud et al. 2004; Anthony et al. 2007), flow (e.g., Dennison and Barnes 1988), and nutrition (e.g., Grottoli et al. 2006; Ferrier-Pagès et al. 2010; Wiedenmann et al. 2013). Documenting variability in experimental conditions will allow us to identify areas of coral bleaching experimental design and reporting that would benefit from increased congruence, which will allow for better comparisons among future coral bleaching experiments.

Goal 3 To quantify the diversity of coral response variables measured in heat-stress experiments and how they are standardized.

Coral bleaching experiments are often designed with interest in specific aspects of the coral response, which could limit the extent of cross-study comparisons. Identifying where there are potential gaps of knowledge or biases in the literature will provide a framework for developing best practice recommendations for coral bleaching experiments, which is the topic of a companion paper developed during the 2019 Coral Bleaching Research Coordination Network workshop (Grottoli et al. 2020).

\section{Methods}

\section{Literature search}

This review focuses on publications that conducted heatstress experiments on corals. A literature search was initiated using the ISI Web of Science database and search engine using the following string to identify relevant peerreviewed publications: Title $=$ coral, Topic $=$ temperature AND bleach*. The initial search returned 1144 publications from 1992 to April 2019. We acknowledge that this approach has the inherit caveat that we may have missed relevant publications. Each publication was examined to assess if the study included the following elements: (1) an experimentally elevated temperature (thus excluding observational surveys conducted after natural bleaching events and reciprocal transplant/common garden experiments), (2) samples that were between the gamete and adult coral life stages (excluding host-tissue explants, $e x$ hospite and culture-grown Symbiodiniaceae and other microbes), and (3) at least one coral species in the order Scleractinia. The 1144 publications were checked twice to 
minimize the likelihood of omitting studies which met the above criteria. Two hundred and forty-three publications met all criteria. We recognize that these publications are not a comprehensive list of all papers that have been published on heat-stress experiments in Scleractinian corals, but a subsample based on our search criteria. However, we believe that 243 is a suitably large enough sample size to truly represent the population of literature which has been published on coral bleaching experiments. In some instances, multiple publications were found to report different aspects of the same heat-stress experiment (e.g., Rodrigues and Grottoli, 2006; Rodrigues et al. 2008). However, because duplication was often not consistently explicit, all publications were treated as independent experiments to avoid erroneously omitting or merging studies. Similarly, twelve publications $(<5 \%)$ included descriptions of two or more different experiments. These were divided into separate studies, bringing the total number of heat-stress experiments to 255. The data for this review were collected between April and June 2019.

\section{Data collection}

The collated data were split into three sections and correspond to each goal: (1) temporal, spatial, and taxonomic information, (2) experimental design information, and (3) measured coral response variables.

\section{Goal 1: Temporal, spatial, and taxonomic information}

Eleven parameters were used to categorize the temporal, spatial, and taxonomic information within each publication (Table 1.1). Temporal information included the year of publication and the month and year the experiment began. Spatial information included the location and geographic coordinates of the experimental setup and the coral collection site. Taxonomic information was recorded to identify the most commonly investigated species, genus, and family. Taxonomic classifications were updated according to Montgomery et al. (2019), and the following nine species were reclassified: Acropora formosa to $A$. muricata, A. surculosa to A. hyacinthus, A. nobilis to A. intermedia, Diploria strigosa to Pseudodiploria strigosa, Favia favus to Dipsastrea favus, Fungia granulosa to Pleuractis granulosa, Goniastrea aspera to Coelastrea aspera, Montastrea faveolata to Orbicella faveolata, Montastrea annularis to Orbicella annularis. It is important to note that we relied on the species designations used by the authors of each publications. However, we recognize that taxonomic uncertainty is potentially another contributor to the observed variation in coral heat-stress responses reported in the literature. For example, recent advances in molecular techniques have revealed that the majority of colonies previously referred to as Pocillopora damicornis in Kāne'ohe Bay, HI were actually Pocillopora acuta (Johnston et al. 2018). While it is outside of the scope of this review to account for potential errors such as this, we highlight that accurate identification of coral species is paramount to move the field forward. Finally, the life stages were recorded as either larval availability (henceforth referred to as pre-settlement life stages), larval settlement, post-settlement juveniles, or adult coral, following the guidelines designated by Ritson-Williams et al. (2009).

\section{Goal 2: Experimental design information}

Experiments were divided into three categories based on the maximum heat-stress duration according to definitions developed in Grottoli et al. (2020) as follows: (1) shortterm experiments with heat-stress exposures of $7 \mathrm{~d}$ or less, (2) moderate-term experiments with heat-stress exposures of 8-30 d, and (3) long-term experiments with heat-stress exposures of more than $30 \mathrm{~d}$. These categories help to differentiate between heat-shock experiments (short term), and those designed to mimic moderate and longer duration natural heat-stress events (Grottoli et al. 2020). Twentyseven categorical and quantitative design parameters were recorded regarding the treatment factors, parent colonies and controls (Table 1.2.a), experimental timeline and temperature conditions (Table 1.2.b), light conditions (Table 1.2.c), and the seawater and tank conditions (Table 1.2.d). The overall design of the three experimental categories (short term, moderate term, and long term) were compared.

\section{Goal 3: Measured coral response variables}

The number and type of coral response variables quantified within each experiment were recorded, as well as information regarding the methods of standardization used for two of the most commonly measured variables of total chlorophyll and endosymbiotic algal density (Table 1.3.1-4). Twenty response variables were identified and grouped into the following categories: bleaching phenotype (Table 1.3.4.a), photosynthetic capacity (Table 1.3.4.b), holobiont phenotype (Table 1.3.4.c), Symbiodiniaceae type (Table 1.3.4.d), or other traits (Table 1.3.4.e).

\section{Data analyses}

The global distribution of the coral collection sites for heatstress experiments was visualized using ArcMap v10.7. Analysis of similarities (ANOSIM) was used to determine if and how the three categories of heat-stress experiments 
Table 1 Information collected from coral heat-stress experiments between 1992 and April 2019 included in this review. Data were split into three sections: (1) temporal, spatial, and taxonomic information, (2) experimental design information, and (3) measured coral response variables

1. Temporal, spatial, and taxonomic information

(1) Year of publication

(2) Date experiment began $^{\mathrm{a}}$

(3) Years between start of experiment and publication (determined from 1 and 2 above)

(4) Experiment location ${ }^{\mathrm{b}}$

(5) Coral collection site

(6) Latitude and longitude ${ }^{\mathrm{d}}$ of experiment location

(7) Latitude and longitude ${ }^{\mathrm{d}}$ of coral collection site

(8) Latitudinal distance ${ }^{\mathrm{e}}$ between collection site and experiment location (determined from 6 and 7 above)

(9) Coral family, genus, and species name

(10) Number of coral species per experiment

(11) Coral life stage (pre-settlement life stages, larval settlement, post-settlement juveniles, or adult)
2. Experimental design information

(a) Treatment factors, parent colonies, and controls

(1) Number of treatment factors $^{\mathrm{f}}$

(2) Type of treatment factors ${ }^{g}$

(3) Number of parent colonies ${ }^{\mathrm{h}}$ sampled

(4) If parent colony was a controlled factor ${ }^{\mathrm{i}}$

(5) If time-zero control was collected $^{\mathrm{j}}$

(b) Experimental timeline and temperature conditions

(1) Coral healing period ${ }^{\mathrm{k}}$ duration $(\mathrm{d})$

(2) Coral acclimation ${ }^{\mathrm{m}}$ duration (d) ${ }^{1}$

(3) Temperature-ramping period $^{\mathrm{n}}$ duration $(\mathrm{d})$

(4) Temperature-stress exposure $^{\mathrm{o}}$ duration (d)

(5) Post-stress recovery duration $(\mathrm{d})^{\mathrm{p}}$

(6) Seawater temperature above control $\left({ }^{\circ} \mathrm{C}\right)^{\mathrm{q}}$

(7) Temperature ramp rate $\left({ }^{\circ} \mathrm{C} \mathrm{h}^{-1}\right)^{\mathrm{r}}$

(c) Light conditions

(1) Natural or artificial lighting

(2) Type of artificial lighting

(3) Indoor or outdoor tanks

(4) Mean light intensity ( $\mu \mathrm{mol}$ photons $\left.\mathrm{m}^{-2} \mathrm{~s}^{-1}\right)^{1}$

(5) Maximum light intensity ( $\mu$ mol photons $\mathrm{m}^{-2} \mathrm{~s}^{-1}$ )

(6) Light-dark cycle (h)

(d) Seawater and tank conditions

(1) Flow-through, recirculating, or static tank system

(2) Natural or artificial seawater

(3) Unfiltered or filtered seawater

(4) Seawater filter type

(5) Coral feeding regime $\mathrm{s}^{\mathrm{s}}$

(6) Number of replicate tanks per treatment

(7) Experimental tank

volume (1)

(8) Tank turnover rate $\left(\mathrm{lh}^{-1}\right)^{\mathrm{t}}$

(9) Seawater flow rate within tanks $\left(\mathrm{cm} \mathrm{s}^{-1}\right)^{\mathrm{u}}$
3. Measured coral response variables

(1) Number of response variables measured

(2) Method of normalization/standardization ${ }^{\mathrm{v}}$

(3) Surface area method [if applicable] (e.g., wax dip, foil, image analysis)

(4) Type of response variables measured:

(a) Bleaching phenotype

(i) Symbiodiniaceae density (cells $\mathrm{cm}^{-2}$, mitotic index)

(ii) Photosynthetic pigments (Chlorophyll concentration)

(iii) Color or optical characteristics (e.g., spectral reflectance)

(iv) Photosynthesis rate (also belongs to photosynthetic capacity category)

(b) Photosynthetic capacity

(i) Chlorophyll fluorescence (typically measured using pulse amplitude (PAM) fluorometry)

(ii) Photosynthesis rate

(c) Holobiont phenotype

(i) Mortality (survival and partial tissue mortality)

(ii) Skeletal growth (calcification and skeletal extension)

(iii) Respiration rate

(iv) Energy reserves (total lipid, protein or carbohydrate content)

(v) Heterotrophy (i.e., Artemia, zooplankton, dissolved and particulate organic carbon)

(vi) Tissue growth (biomass, tissue thickness)

(vii) Reproduction (response variables associated with pre-settlement life stages)

(d) Symbiodiniaceae identification

(i) Symbiodiniaceae

(e) Other traits

(i) Immunological compounds

(ii) Gene expression

(iii) Nutrient cycling within holobiont

(iv) Microbiome ${ }^{\mathrm{w}}$

(v) Metabolites (a substance formed in or necessary for metabolism)

(vi) Proteomes (protein sets) 
Table 1 continued

${ }^{a}$ Day on which temperatures in the stress-treatment tanks were increased above that of the controls. In most cases, only month and/or year were reported

${ }^{\mathrm{b}}$ Country, state, city/island, and laboratory facility name

${ }^{\mathrm{c}}$ Ocean basin/region (Caribbean, Central Pacific, Indo-Pacific, Atlantic, Mediterranean, Red Sea, or Indian Ocean), country, island, and reef name. For the purposes of this review, locations to the north of the Philippine Sea and the South China Sea were considered Central Pacific, as opposed to Indo-Pacific

${ }^{\mathrm{d}}$ Values in degrees and minutes only, not seconds

${ }^{\mathrm{e}}$ The distance between each degree of latitude is between 110.5 and $111.6 \mathrm{~km}$, depending on location. For the purposes of this review, $111 \mathrm{~km}$ was used

${ }^{\mathrm{f}}$ Single-factor designs manipulated only one explanatory variable (i.e., temperature). Multiple-factor designs manipulated two or more explanatory variables

${ }^{\mathrm{g}}$ In addition to temperature, for example: $\mathrm{pH}$, light, turbidity, nutrients

${ }^{\mathrm{h}}$ Author(s) specified that separate parent colonies were collected. However, in most cases, no testing was conducted to confirm genetic identity. We assumed that these colonies represented separate parent colonies (or genets)

${ }^{\mathrm{i}} \mathrm{A}$ fragment from every parent colony was represented under every treatment condition

${ }^{\mathrm{j}} \mathrm{A}$ coral fragment, was archived before the onset of temperature stress, representing a pre-treatment control

${ }^{\mathrm{k}}$ Number of days between coral collection from the reef or fragging (genet is cut into multiple smaller ramets using bone cutters or a similar tool) and placement into experimental tanks

${ }^{1}$ In situations where authors reported a range of numerical values, the midpoint of the range was recorded. Example 1: "corals were allowed to acclimate for 10 to 20 days", the midpoint value is 15 days. Example 2: "on average, tanks received between 200 and 300 umol photons $m^{-2} s^{-1}$ of light", the midpoint value is $250 \mu \mathrm{mol}$ photons $\mathrm{m}^{-2} \mathrm{~s}^{-1}$

${ }^{\mathrm{m}}$ Number of days corals were in the experimental tanks, acclimating to ambient conditions before the experiment formally began

${ }^{\mathrm{n}}$ Number of days over which the seawater in the stress-treatment tanks was heated from the initial temperature (same as control) to the desired stress temperature

${ }^{\circ}$ Number of days corals were exposed to stress-treatment temperature (not including the ramping period)

${ }^{\mathrm{p}}$ Number of days of post-stress monitoring of coral health/physiology after the temperature in the stress-treatment tanks was lowered back to the control treatment

${ }^{\mathrm{q}}$ The difference in temperature between the control treatment and the stress treatment. In cases where experiments had multiple temperature treatments, multiple values were recorded and treated as independent when calculating the mean temperature stress above control (Table S4.b.6)

${ }^{\mathrm{r}}$ Rate of seawater temperature increase in the stress-treatment tanks during the ramping period

${ }^{\mathrm{s}}$ Coral feeding regime, frequency and type (e.g., 200 Artemia per ml seawater twice a week for $1 \mathrm{~h}$ )

tTime for all seawater to be replaced within a tank, typically measured using a graduated cylinder and a stopwatch

u'Seawater circulation speed in the experimental tanks, typically measured using a ruler and dye/beads

${ }^{v}$ Normalization method (e.g., standardized to surface area or biomass/ash-free dry weight) used for the most commonly measured response variables of Symbiodiniaceae density and chlorophyll concentration to assess the continuity in reporting units among studies

${ }^{\mathrm{w}}$ Any characterization of bacteria, archaea, viruses, and or microeukaryotes associated with a coral

differed from each other, and the data were visualized using a non-metric multidimensional scaling (NMDS) plot using six design parameters: number of coral species per experiment (Table 1.1.10), number of treatment factors (Table 1.2.a.1), the number of parent colonies sampled (Table 1.2.a.3), seawater temperature above control (Table 1.2.b.1), temperature ramp rate (Table 1.2.b.2), and number of response variables measured (Table 1.3.1). These parameters were chosen for multivariate analysis because they were the most commonly reported. Since only experiments that reported values for all parameters could be included in the multivariate analyses, the sample size for each category of experiment was as follows: 50 short-term, 49 moderate-term and 9 long-term experiments.
Temperature ramp rate and the number of parent colonies sampled were log-transformed to improve normality. All parameters were then standardized before constructing a Euclidean-distance dissimilarity matrix. The design parameters that most contributed to the separation among groups were identified using NMDS vector correlation analysis and similarity percentage analyses (SIMPER). Experimental temperature timelines were generated for each heat-stress duration category using seawater temperature above control (Table 1.2.b.1), and the median durations of healing, acclimation, ramping, stress-exposure, and recovery periods (Table 1.2.b.3-7). Median duration values were used because of the large variation in the data that limited the utility of presenting mean values. Throughout 
this review, the prevalence of underreporting methodological information within each publication was quantified. All statistical analyses were prepared using the statistical software R (R Core Development Team 2017) and PRIMER V6 (Clarke and Gorley 2006).

\section{Results and discussion}

\section{Goal 1: Temporal, spatial, and taxonomic information}

Of the 255 experiments reviewed, almost half were published within the last 5 years (i.e., 2014 to April 2019) (Table S1.1, Fig. S1a). Although the total number of experiments published every year continually increased (Fig. S1a), the greatest number of experiments were initiated in 2011-2012 (Fig. S1b). The month and year experiments began were not reported in $40 \%$ and $36 \%$ of studies, respectively (Tables S1.2). On average, it took $3.9 \pm 2.2$ years (mean $\pm \mathrm{SD}$ ) for the results to be published (Table S1.2-1.3) after experiments began.

\section{Experiment location and coral collection site}

Over the last 30 years, coral heat-stress experiments were conducted in 26 countries and territories (Table S1.4). However, this is almost certainly an underestimate as almost a quarter of studies failed to report experiment location (Table S1.4). Out of the 196 studies that did report experiment location, the largest proportion took place in Australia (39\%), USA (20\%, of which nearly three-quarters were in either Hawaii or Florida) and Japan (6\%) (Table S1.4).

Unlike experiment location, coral collection site was always reported, but with varying degrees of specificity, ranging from exact geographic coordinates for a single reef (e.g., Kirk et al. 2018) to basin-level categorizations (e.g., Rosado et al. 2019). The majority of the corals used in heat-stress experiments were collected from reefs in the Indo-Pacific (48\%), followed by the Caribbean (17\%), Central Pacific (15\%), and Red Sea (12\%) (Table S1.5). While the variety of coral collection sites was high, there were several hotspots for coral heat stress and bleaching research that do not necessarily represent the global distribution of tropical shallow reefs (Fig. 1). Several ocean regions (including Thailand, western Indian Ocean, and southern Great Barrier Reef) have been identified as potential areas of thermal refugia for corals over the next few decades (van Hooidonk et al. 2013; Cacciapaglia and van Woesik 2015). However, our results show that corals from these regions are heavily understudied and, in some cases, appear to have never been included in a heat-stress experiment (Fig. 1). These understudied reefs are potential gaps in the existing literature, limiting our understanding of how corals in those regions may respond or acclimatize to heat stress and bleaching.

Of the 133 studies which reported latitude (or provided enough information to derive latitude) for both experiment location and coral collection site, $14 \%$ of studies transported their corals more than $1000 \mathrm{~km}$ (or approximately ten degrees latitude) north or south to the experimental location (Table S1.8). It is unclear what the total effects of the long-distance transport may be, but the majority of experiments did not account for the distance between collection site to experimental location in their experimental design or data interpretation. A potential problem with transporting corals prior to experimentation could be that the timing of the heat-stress experiment does not coincide with the natural timing of bleaching events at the site of origin. Similarly, the mean monthly maximum solar irradiance values differ significantly between summer and

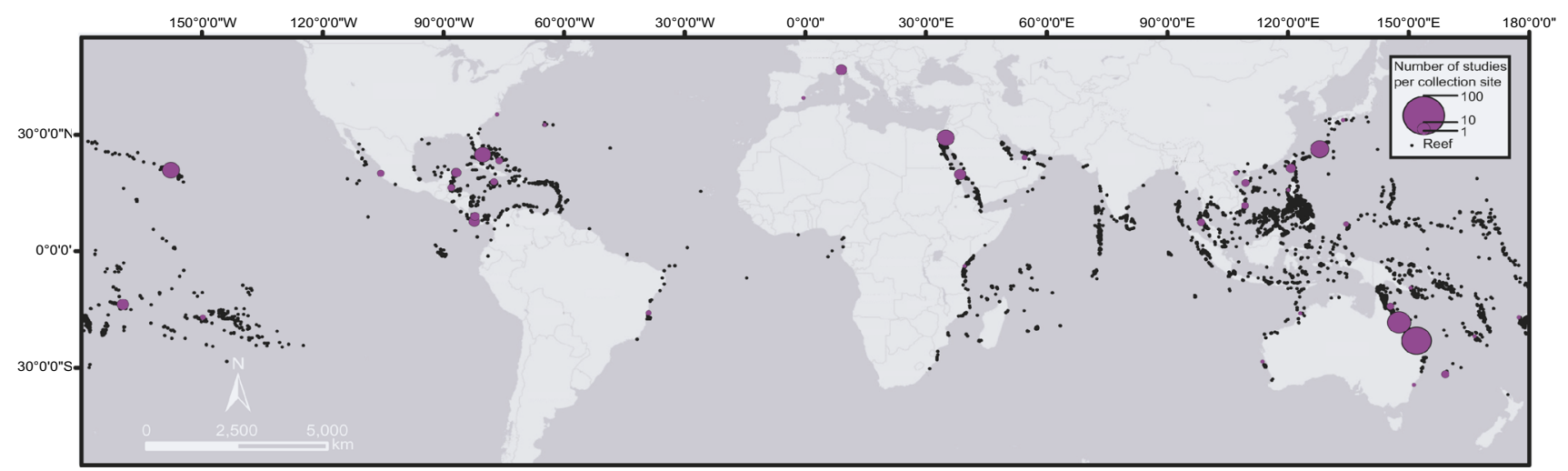

Fig. 1 Global distribution of tropical and subtropical shallow water coral reefs (black circles) and coral collection site hotspots (purple circles) for heat-stress experiments between 1992 and April 2019 included in this review. The size of purple circles is proportional to the number of studies that reported collecting coral samples within five degrees of the center. Data for known coral reef locations (black circles) are from the Global Coral Disease Database (UNEP-WCMC 2018). Service Layer Credits: ESRI, HERE, DeLorme 
winter, which has serious implications for corals in outdoor experiments under natural sunlight. This is an important consideration that may affect the outcome of an experiment, as coral resistance to heat stress is known to differ for some species between summer and winter. For example, photosynthesis rates are often higher in the summer, whereas corals may be more susceptible to photodamage and pigment loss in the winter (e.g., Scheufen et al. 2017).

\section{Coral species and life stage}

In total, 106 different Scleractinian species from 39 genera and 17 families were included in heat-stress experiments over the last 30 years (Table S2). Of the 255 studies, most investigated species belonging to the family Acroporidae (63\%), Pocilloporidae (42\%), and Poritidae (27\%) (Fig. 2). Globally, the three most commonly studied species were Pocillopora damicornis (21\%), Stylophora pistillata
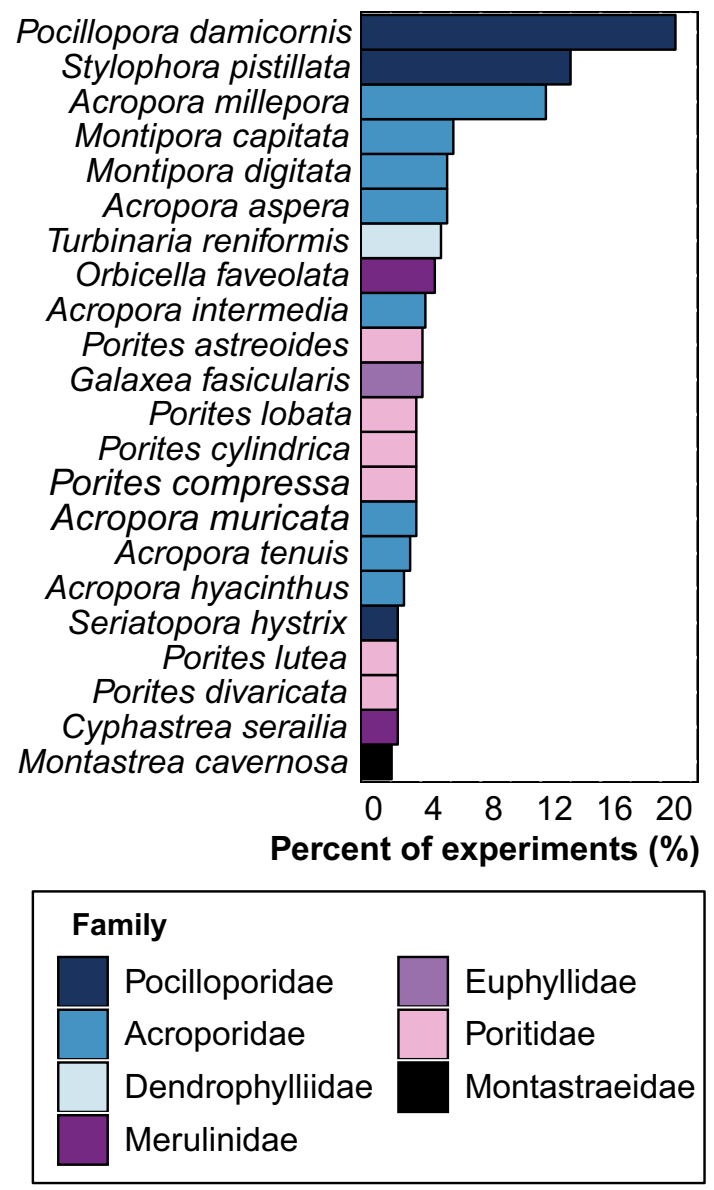

Fig. 2 Scleractinian coral families, genera, and species investigated in 255 heat-stress experiments between 1992 and April 2019 included in this review. Note that several studies included more than one species, thus percentages shown sum to more than $100 \%$. Species which were included in more than $2 \%$ of the experiments are depicted above, and a comprehensive list can be found in Table S2. Species are color-coded by the taxonomic family to which they belong
(15\%), and Acropora millepora (12\%) (Fig. 2). In the Caribbean, the most commonly studied species were $\mathrm{Or}$ bicella faveolata (33\%) and Porites astreoides (23\%) (Table S3). In the Central Pacific, the most frequently studied species were Montipora capitata (36\%), Porites compressa (23\%), and Pocillopora damicornis (21\%) (Table S3). Within the Indo-Pacific, the most commonly studied species were Pocillopora damicornis (29\%) and Acropora millepora (25\%) (Table S3). Finally, from the Red Sea, the most commonly studied species were Stylophora pistillata (55\%) and Turbinaria reniformis (21\%). The ratio of species investigated to number of experiments conducted within ocean basins ranged from 0.54 to 0.69 (Table S3). Overall, these data show that a small number of coral species are favored for coral heat-stress experimentation. This could be because of the ease of applying the existing knowledge on these highly studied species, because of the ubiquity of these species within each region, or because of logistical constraints (e.g., permitting, differential survivorship in captivity). Studying coral heatstress responses in a few target species is advantageous in providing a large library of knowledge on the more abundant reef-building corals on both local and ocean-basin scales. However, a disadvantage of this approach is that numerous coral species with diverse traits remain understudied. To date, only a third of studies have investigated two or more coral species concurrently (Table S1.10). Moving forward, incorporating greater numbers of coral species (especially those which are currently understudied) into heat-stress experiments will be key to building a more comprehensive catalog of coral responses to rising seawater temperatures.

A gap in the literature was identified regarding the life stages of corals studied. More than $95 \%$ of the studies investigated the effects of elevated temperature on adult corals, $2 \%$ on pre-settlement life stages, $1 \%$ on larval settlement, and $1 \%$ on post-settlement juveniles (Table S1.11). Interestingly, no studies investigating the effects of elevated temperature on gametes were found (Table S1.11). We recognize that our search criteria did miss some publications on these earlier life stages (e.g., Edmunds et al. 2001; Cumbo et al. 2013; Ritson-Williams et al. 2016). However, our results do effectively demonstrate that the proportion of studies which have been conducted on these earlier life-history stages is very low. There could be several reasons for this disparity, including logistical difficulties with collecting gametes and larvae, as their availability is temporally limited (e.g., Babcock et al. 1986; Szmant 1986; Richmond and Hunter 1990). While there are several challenges associated with the sexual reproduction of corals in captivity (see reviews by Petersen et al. 2007; Petersen 2008), reports of successful ex situ spawning have increased in recent years (e.g., Craggs et al. 
2017). Regardless of the reason, the heat-stress and coralbleaching responses of these earlier life stages are critically understudied. A major drawback associated with investigating adult corals in isolation is that researchers cannot consider linkages that might exist among life stages or across generations (i.e., parental and epigenetic effects) (Marshall and Morgan 2011). For example, larvae of the brooding species Pocillopora damicornis were able to acclimate to elevated temperature inside parental polyps (Putnam and Gates 2015). However, in Porites astreoides, short-term heat-stress had no effect on larval survival or settlement and overall recruitment was significantly reduced due to elevated post-settlement mortality in the juvenile coral spats (Ross et al. 2013). Therefore, it is crucial to investigate the effects of heat stress across multiple life stages to accurately predict the evolutionary potential of coral reefs in a rapidly changing climate (Putnam and Gates 2015).

\section{Goal 2: Experimental design information}

More than half $(51 \%)$ of the heat-stress experiments were short term, whereas $36 \%$ and $12 \%$ were moderate- or long term, respectively (Table S4). Four studies could not be placed into any of these categories as they continually ramped the temperature in their tanks and thus did not have a defined heat-stress-exposure duration (Table 1.2.b.6). Considering the most commonly reported six of a total of 27 design parameters together (i.e., number of species, number of treatment factors, number of parent colonies, seawater temperature above control, temperature ramp rate, and number of response variables measure), an ANOSIM revealed that short-term heat-stress experiments significantly differed from both moderate-term and long-term experiments, and the moderate- and long-term experiments were considerably different from each other $(p=0.058)$ (Table S5). Vector analyses and SIMPER analyses indicated that the number of parent colonies sampled and the seawater temperature ramp rate $\left({ }^{\circ} \mathrm{C} \mathrm{h}^{-1}\right)$ were large contributors to the observed separation between these heatstress duration categories (Table S5, Fig. S2). The ramp rates were fastest and sample sizes smallest in the shortterm experiments followed by the moderate- and long-term experiments.

\section{Treatment factors}

The percentages of single-factor (temperature only) versus multiple-factors designs were approximately equal at 53\% and $47 \%$, respectively (Table S4.a.1). Manipulating seawater temperature under controlled experimental conditions (where all other confounding variables are accounted for), allows researchers to test hypotheses related to the direct effect of temperature on the response variables of interest. Yet, as the effects of elevated temperature on the status of coral reefs have become clearer, understanding the interactions between temperature and other environmental stressors has become increasingly valuable. For example, it has been shown that bleaching susceptibility can increase under elevated concentrations of dissolved inorganic nitrogen (e.g., Wiedenmann et al. 2013). Similarly, the response of corals to heat-stress varies among species when simultaneously exposed to ocean-acidification conditions (e.g., Schoepf et al. 2013). For short-term studies, temperature and light were manipulated concurrently in a quarter of the experiments, and temperature and nutrients in another $8 \%$ (Table S4.a.2). In moderate-term experiments, temperature and light (12\%), temperature and feeding (11\%), and temperature and acidification (9\%) were most commonly evaluated (Table S4.a.2). In longterm studies, almost a quarter applied temperature and acidification stress, and $17 \%$ manipulated temperature and light (Table S4.a.2). Another strength of multiple-factor and multi-level designs is that they allow researchers to construct reaction norms - a tool used to describe the pattern of phenotypic expression of a single genotype across a range of environments. While the application of reaction norms was nearly absent in the coral heat-stress experiments reviewed here, more researchers should consider incorporating such approaches moving forward, as they have been shown to be an invaluable tool used to model and predict the response to species to environmental stress in several other fields (Angilletta Jr. 2009).

\section{Parent colonies and temporal controls}

Only $4 \%$ of studies conducted genetic analyses on the parent colonies they collected to confirm that their samples were genetically distinct and were not clones (ramets). Instead, most publications reported that parent colonies were selected with some criteria in mind to avoid potentially replicating genets within an experiment, such as choosing corals with a minimum distance between them. Regardless of the method used to differentiate genets, the number of parent colonies sampled varied between heatstress duration categories. Short-term experiments typically sampled from three to four parent colonies $(25 \%)$, unlike moderate- and long-term studies which frequently sampled from ten or more parent colonies (29\% and 33\%, respectively) (Table S4.a.3). Surprisingly, a fifth of all heat-stress experiments used between one and three parent colonies (Table S4.a.3). Given that a minimum of four genets is needed to sustain $80 \%$ of allelic variability in a coral population (Baums et al. 2019), studies with fewer than four parent colonies may have biased results that are not sufficiently representative of the coral population in 
questions. It is important to note that the clarity with which sampling information is often presented has significant room for improvement, as $25 \%$ of experiments were unclear, reporting that "five corals" or "five fragments" were collected, but never specifying whether the fragments originated from single or multiple parent colonies (Table S4.a.3). Many publications failed to report the number of parent colonies sampled $(9 \%)$ or whether parent colony was a controlled factor in the experimental design (34\%) (Fig. 3a, Table S4.a.3-a.4). Only 17\% of experiments archived fragments at the beginning of the experimental period as a time-zero control (Table S4.a.5). By doing so, researchers can identify how the tank incubation itself has affected corals during the experimental period, thus improving the application of results to the natural environment. The observed infrequency of such temporal controls may be because of limitations such as collection permit restrictions or limited space within tanks for additional fragments.

\section{Experimental timeline and temperature conditions}

The timeline of experiments varied substantially between the three heat-stress duration categories. The median
Fig. 3 Percentage of coral heatstress experiments between 1992 and April 2019 included in this review that reported (solid bars) or did not report (dashed bars) experimental design information. Solid and dashed bars are subdivided into heatstress duration categories: shortterm (dark blue), moderate-term (light blue), and long-term (purple). Four groups of experimental design information are illustrated: (a) treatment factors, parent colonies, and controls,

(b) experimental timeline and temperature conditions, (c) light conditions, and (d) seawater and tank conditions. The following four experimental design variables were not included in the above figure as they were not applicable to all experiments: if time-zero control was collected, poststress recovery duration, type of artificial lighting, and coral feeding regime. A comprehensive list of reporting statistics for all variables can be found in Table S4.a-d

\section{a Treatment factors, parent colonies, and controls}

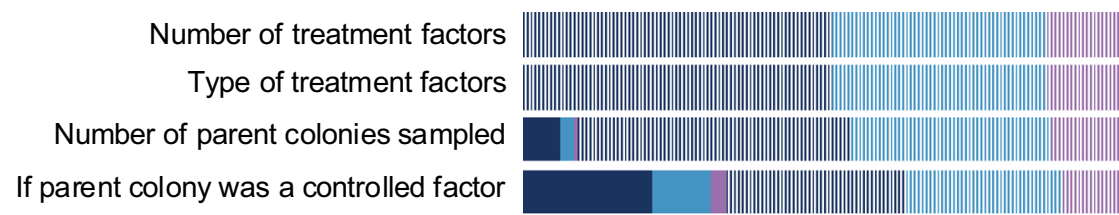

b Experimental timeline and temperature conditions

Seawater temperature above control $\mid \|_{1}$

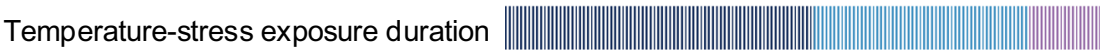
Temperature ramp rate Coral acclimation duration Temperature-ramping period duration Coral healing period duration

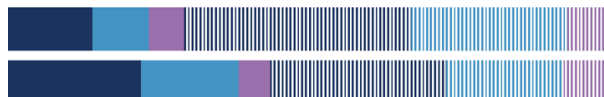

C Light conditions

$$
\begin{array}{r}
\text { Natural or artificial lighting } \\
\text { Indoor or outdoor tanks } \\
\text { Mean light intensity } \\
\text { Maximum light intensity } \\
\text { Light-dark cycle }
\end{array}
$$

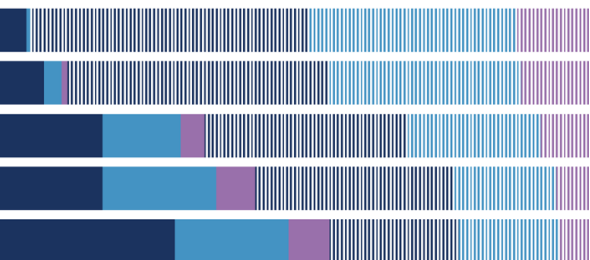

\section{d Seawater and tank conditions}

Flow-through, recirculating, or static tank system

Natural or artificial seawater

Number of replicate tanks per treatment

Experimental tank volume

Unfiltered of filtered seawater

Tank turnover rate

Seawater flow rate within tanks

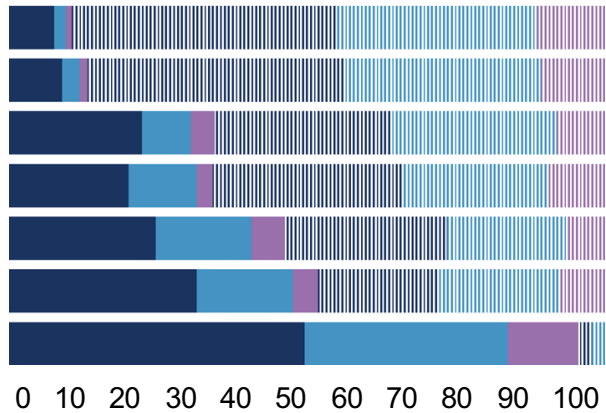

Percent of experiments (\%)

Short-term not reported

Short-term reported
Moderate-term not reported

Moderate-term reported
Long-term not reported

Long-term reported 
number of days between coral fragmentation and the start of the experiment (i.e., the sum of healing period duration and coral acclimation duration) for short-term studies was $4 \mathrm{~d}$, which was four times shorter than moderate-term experiments (16 d) and six times shorter than long-term (24 d) (Fig. 4a, Table S4.b.1-b.2). Surprisingly, 44\% of studies did not report the duration of the healing period and $29 \%$ did not report the length of acclimation that each coral received before the onset of heat stress (Fig. 3b). The fragmentation of corals and movement to new environments presents a potentially stressful event, regardless of how seemingly moderate the new treatment conditions may be with tissue lesion healing taking up to $30 \mathrm{~d}$ (Lirman 2000) and with observable shifts in the microbiome (Thurber et al. 2009). This highlights the importance of a healing and acclimation period prior to the start of a heatstress experiment, and the importance of reporting the duration of both periods.

The heat-stress temperature applied across all experiments was extremely varied and ranged from +0.8 to $+15^{\circ} \mathrm{C}$ above the control temperature, with an average of $4.9 \pm 2.3{ }^{\circ} \mathrm{C}$ (mean $\pm \mathrm{SD}$, Table S4.b.6). The mean heatstress temperature for short-, moderate-, and long-term studies was $5.2 \pm 2.3{ }^{\circ} \mathrm{C}, 4.3 \pm 2.0^{\circ} \mathrm{C}$, and $4.9 \pm 2.8^{\circ} \mathrm{C}$
( \pm SD), respectively (Fig. 4c, Table S4.b.6). The high experimental bleaching temperatures may be a consequence of most studies being short-term in design, which require rapid increases in temperature to rapidly reach a bleached state, or an artifact of experiments applying multiple levels of heat stress to ensure bleaching. Alternatively, if experiments were conducted in winter months (when ambient temperatures were naturally low) then substantial heating (e.g., $+5{ }^{\circ} \mathrm{C}$ ) would be necessary to reach bleaching thresholds.

The combination of heat-stress temperature and duration defines the degree of stress that corals experience in an experiment. The same parameters are used to predict coral bleaching and mortality in nature and is often reported in degree heating weeks units (e.g., Strong et al. 2006). The mean temperature ramp rate of short-term studies was almost two and a half times higher than moderate-term experiments and more than 4 times higher than that of long-term experiments (Table S4.b.7). Overall, the rate of temperature increase across all studies was much higher than expected (mean \pm SD: $1.2 \pm 2.2{ }^{\circ} \mathrm{C} \mathrm{h}^{-1}$, median: $0.08{ }^{\circ} \mathrm{C} \mathrm{h}^{-1}$ ) (Table S4.b.7). Unfortunately, seawater temperature ramp rate was not reported in almost a third of papers reviewed (Fig. 3b, Table S4.b.7). Interestingly, 21\%

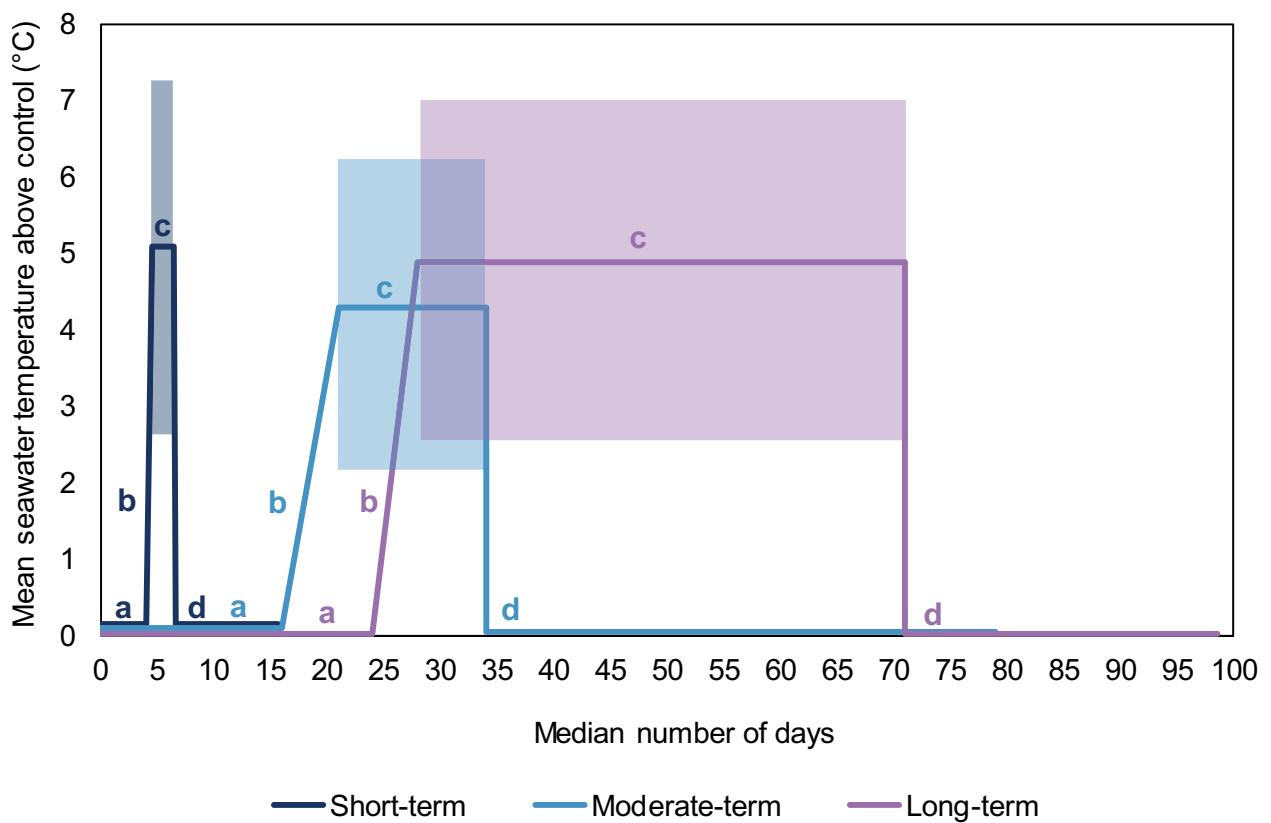

Fig. 4 Experimental temperature timelines for short-term (dark blue), moderate-term (light blue), and long-term (purple) coral heatstress experiments between 1992 and April 2019 included in this review. Shown are the: (a) number of days pre-stress during which corals are maintained at control temperature (i.e., sum of coral healing and acclimation durations), (b) the temperature-ramping duration, (c) mean stress-exposure temperature above control $( \pm 1 \mathrm{SD}$ in shaded boxes) and duration, and (d) the post-stress recovery duration. See supplemental information for summary statistics and percentage data for: seawater temperature above control (Table S4.b.6), coral healing period duration (Table S4.b.1), coral acclimation duration (Table S4.b.2), temperature-ramping duration (Table S4.b.3), temperature-stress-exposure duration (Table S4.b.4), and post-stress recovery duration (Table S4.b.5). Note that the median number of days over which temperature was ramped is depicted here, not the average ramp rate. Temperature ramp rate statistics are summarized in Table S4.b.7) 
of short-term experiments used no ramping period, and instead moved corals from the control temperature tank to the elevated temperature tank instantaneously (Table S4.b.7). The differential impacts of such varied water-heating strategies must be considered carefully when interpreting coral responses and extrapolating results to natural reef systems.

\section{Light conditions}

A larger proportion of coral heat-stress experiments were conducted using artificial lighting (52\%) versus natural sunlight (42\%) (Table S4.c.1), with $6 \%$ of studies failing to report light information (Fig. 3c). Of the 132 experiments with artificial light, $42 \%$ used metal halide lamps, $15 \%$ fluorescent lights, and 11\% light-emitting diodes (LEDs) (although the latter only became common within the last ten years as they become more widely available) (Table S4.c.2). This variation is potentially problematic for cross-study comparisons because of differences in the distribution and spectra of light and heat emitted by each type of artificial light source (reviewed by Osinga et al. 2008). For instance, under light fixtures that emit greater proportions of blue light, rather than red light, corals can have higher survival rates, growth rates, and Symbiodiniaceae densities (Wijgerde et al. 2014).

The proportion of experiments which were conducted outdoor under natural light was seen to increase as the duration of the heat-stress exposure increased (Table S4.c.3). However, $12 \%$ of studies did not report if tanks were indoors or outdoors (Fig. 3c, Table S4.c.3). A striking difference in light intensity was found between indoor and outdoor tanks, with mean light intensities of 227 and $429 \mu \mathrm{mol}$ photons $\mathrm{m}^{-2} \mathrm{~s}^{-1}$, respectively (Table S4.c.4). Similarly, the average maximum irradiance levels reported for outdoor studies $(847 \mu \mathrm{mol}$ photons $\mathrm{m}^{-2} \mathrm{~s}^{-1}$ ) was almost four times as large as that for indoor studies $\left(252 \mu \mathrm{mol}\right.$ photons $\left.\mathrm{m}^{-2} \mathrm{~s}^{-1}\right)$ (Table S4.c.5). Because of their technological limitations, artificial indoor lighting cannot mimic the light intensities and variability of natural sunlight, which has large consequences for studies trying to replicate natural conditions. The mean and maximum irradiance levels during the experimental period were severely underreported in both indoor and outdoor experiments (19-28\% and 53-63\% did not report, respectively) (Fig. 3c, Table S4.c.4, c.5). Similarly, the duration of the light-dark cycle was not reported in $55 \%$ of studies (Fig. 3c). To facilitate meta-analysis and cross-study comparisons, it is crucial to know the light levels under which corals were maintained, as light affects a myriad of coral response variables, such as chlorophyll concentrations (e.g., Dubinsky et al. 1984), coral growth rates (e.g., Falkowski et al. 1984), metabolic production (Khalesi et al.
2009), colony morphology (e.g., Ow and Todd 2010), and color and fluorescent proteins (e.g., D’Angelo et al. 2008). Most importantly, however, high light levels interact with temperature to enhance bleaching (e.g., Lesser et al. 1990), and therefore, reporting light levels is essential to interpreting heat-stress thresholds.

\section{Seawater source and nutrition}

Almost two-thirds of heat-stress experiments used open, flow-through-seawater systems (Table S4.d.1). This was particularly true for the moderate- and long-term studies ( $77 \%$ and $72 \%$, respectively). Conversely, closed systems (recirculating and static tanks) were used in $26 \%$ of all experiments of which the majority were short-term (Table S4.d.1). Unfortunately, tank system type was not reported in $10 \%$ of studies (Fig. 3d). Similarly, $45 \%$ of experiments did not state whether they used natural or artificial seawater (Table S4.d.2). Of those which did, most experiments used natural $(78 \%)$ rather than artificial $(9 \%)$ seawater (Table S4.d.2). Knowing the seawater source used in heat-stress experiments is important because it can affect a variety of physicochemical parameters such as salinity, alkalinity, $\mathrm{pH}$, dissolved oxygen, and nutrients (both organic and inorganic) that can directly affect coral health (see review by Borneman 2008). In terms of seawater filtration, $45 \%$ of experiments used some form of filtration (Table S4.d.3), and $45 \%$ of studies failed to report this information (Fig. 3d). Of the 116 studies which filtered incoming seawater, only $36 \%$ reported the type of filtration used (Table S4.d.4). A variety of methods were observed (e.g., UV, membrane, mesh, cartridge, GF/F), but sand or gravel seawater filtration was most frequently reported (Table S4.d.4). The type and amount of organic matter that can enter and exit experimental systems will vary depending upon the pore size and type of filter used, which in turn, has profound implications for coral heterotrophy. Corals can feed on a wide variety of organic materials including dissolved (e.g., Grover et al. 2008), detrital (Anthony 1999; Anthony and Fabricius 2000), and liveparticulate matter including zooplankton (see review by Houlbrèque and Ferrier-Pagès 2009). Heterotrophy is vital for tissue building and lipid synthesis (Hughes et al. 2010; Baumann et al. 2014) and for supplying coral with important nutrients (such as nitrogen and phosphorus) that cannot be sourced through photosynthesis alone (Houlbrèque and Ferrier-Pagès 2009). Healthy corals can incorporate carbon from heterotrophic sources to meet up to $35 \%$ of daily metabolic demand, and bleached corals without photosynthetic inputs, may rely on these carbon sources almost exclusively (Palardy et al. 2008). Similarly, several studies have shown that heterotrophic carbon sources are key to maintaining carbon budgets and 
facilitating recovery following single bleaching events (Grottoli et al. 2006, 2014; Palardy et al. 2008; Hughes et al. 2010; Hughes and Grottoli 2013; Levas et al. 2013; Baumann et al. 2014). However, only 43 studies (17\%) explicitly stated that corals were fed (e.g., Artemia brine shrimp or zooplankton) during the experimental period (Table S4.d.5). The inclusion of heterotrophic carbon may be less critical for short-term experiments, but more than $60 \%$ of the moderate- and long-term experiments did not feed, or failed to report whether the corals were fed (Table S4.d.5). It is important to acknowledge that limiting access to labile organic material and zooplankton in a heatstress experiment lasting weeks or months could unintentionally affect the results by adding further stress to the corals.

\section{Tanks, flow, and turnover}

The mean number of replicate tanks used per treatment was 3 for short- and moderate-term experiments and 6 for longterm experiments (Table S4.d.6) and the mean volume of each tank increased with heat-stress duration (Table S4.d.7). Unfortunately, the number and size of replicate tanks were not reported in a third of studies (Fig. 3d). More than half of experiments failed to report tank turnover rates and more than $95 \%$ did not report seawater flow within tanks (Fig. 3d, Table S4.d.8 and d.9). Water motion within marine aquaria is important to ensure homogenous mixing of temperature, $\mathrm{pH}$, and dissolved oxygen and is important for metabolism, calcification, particle capture, nutrient uptake, and waste removal from the surface of colonies (reviewed by Leal et al. 2017). In the wild, corals in reefs with increased water flow bleach less intensely than corals from low flow environments (McClanahan et al. 2005). Similarly, when experimentally bleached, corals have higher survival and faster recovery of chlorophyll and Symbiodiniaceae density under moderate to high flow conditions (Nakamura and van Woesik 2001; Nakamura et al. 2003). The absence of adequate reporting of flow conditions is a major gap in the literature that may be contributing to biases in our perception of the high variability in coral bleaching responses and potentially reducing the applicability of findings to understanding natural bleaching events.

\section{Goal 3: Measured coral response variables}

On average, $4 \pm 2$ (mean \pm SD) coral response variables were measured in each heat-stress experiment (Table S6.1) and were predominantly associated with the dinoflagellate endosymbiont rather than the coral host or the holobiont as a whole (e.g., Symbiodiniaceae density, photosynthetic pigments, and chlorophyll fluorescence) (Fig. 5,
Table S6.4.a-b). Bleaching phenotype, photosynthetic capacity, and holobiont phenotype traits were measured in $78 \%, 57 \%$, and $61 \%$ of experiments, respectively (Fig. 6).

\section{Bleaching phenotype}

Bleaching phenotype is a way to record the degree of paleness or photosynthetic function of corals in a heatstress experiment. While most studies measured at least one bleaching phenotypic trait, 22\% did not (Fig. 6). Of those that did, Symbiodiniaceae density (typically standardized to surface area) was the most commonly reported coral-bleaching-phenotype variable, followed by photosynthetic pigments (i.e., chlorophyll), color, and rate of photosynthesis (Fig. 5a, Table S6.2, 6.4.a). However, chlorophyll concentration was evenly split between surface area and Symbiodiniaceae density standardization (Table S6.2). Surprisingly, only a small proportion of these studies standardized their values to biomass $(12 \%)$ or protein content (8\%) (Table S6.2), despite evidence to suggest that such standardizations may be more biologically relevant and less prone to variation because of differences in tissue thickness and skeletal morphology (Edmunds and Gates 2002). Thus, one must be cautious when comparing results among studies as biomass and surface area standardized data are not equivalent (Edmunds and Spencer Davies 1986; Edmunds and Gates 2002). If authors were to make their data available with both surface area and biomass standardization, it would allow better comparison across studies and help reconcile findings among studies. Of the 157 studies which standardized at least one of their measured response variables to surface area, the most commonly used methods were wax dip (41\%, Stimson and Kinzie 1991), foil wrap (24\%, Marsh 1970), and geometric approaches (16\%, e.g., Naumann et al. 2009) (Table S6.3). Unfortunately, 20\% of these studies did not report the methods that were used to quantify surface area (Table S6.3), highlighting the need for common reporting requirements. Improved methodological reporting recommendations are discussed in our companion paper, Grottoli et al. (2020).

\section{Photosynthetic capacity}

Forty-three percent of experiments reviewed did not investigate photosynthetic capacity (Fig. 6). Of those that did, 44 experiments directly measured photosynthesis rate, whereas 124 experiments measured active chlorophyll $a$ fluorescence, primarily via pulse amplitude modulated (PAM) fluorometry (Fig. 5b, Table S6.4.b). A wealth of information regarding the photochemical state of the in hospite Symbiodiniaceae can be determined via chlorophyll $a$ fluorometry, and it has been used to demonstrate 
Fig. 5 Percentage of 255 coral heat-stress experiments between 1992 and April 2019 included in this review that measured each listed coral response variable in the following categories:

(a) bleaching phenotype,

(b) photosynthetic capacity,

(c) holobiont phenotype,

(d) Symbiodiniaceae identification, and (e) other traits. Within each category, response variables are ordered top to bottom from most frequently measured to least. Note: Photosynthesis rate is represented in two categories as it is both a bleaching phenotype trait as well as a photosynthetic capacity trait. Percentage data illustrated above can also be found in Table S6.4a-e

\section{a Bleaching phenotype}

Symbiodiniaceae density

Photosynthetic pigments

Color and optical characteristics

Photosynthesis rate

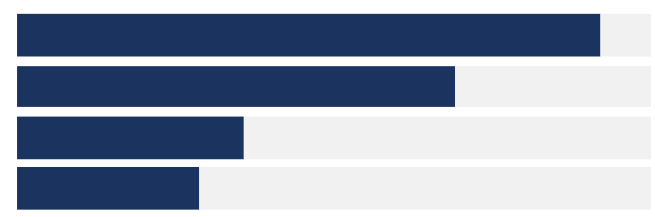

b Photosynthetic capacity

Chlorophyll fluorescence

Photosynthesis rate

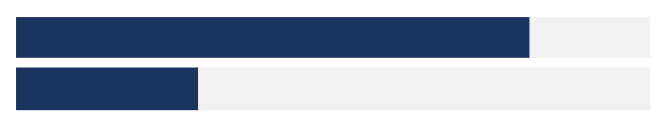

\section{Holobiont phenotype}

$$
\begin{array}{r}
\text { Mortality } \\
\text { Skeletal growth } \\
\text { Respiration rate } \\
\text { Energy reserves } \\
\text { Heterotrophy } \\
\text { Tissue growth } \\
\text { Reproduction }
\end{array}
$$

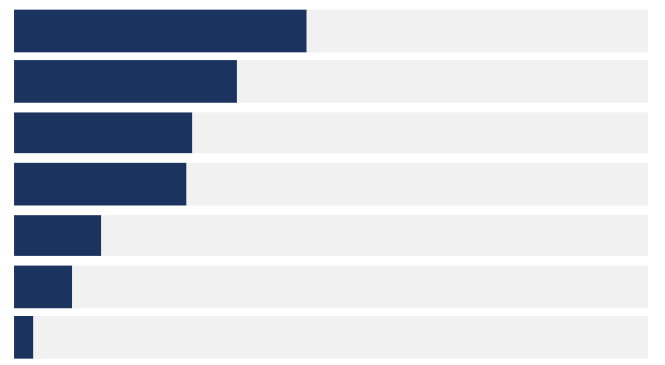

\section{Symbiodiniaceae identification}

Symbiodiniaceae

\section{e Other traits}

Immunological compounds

Gene expression

Nutrient cycling within holobiont

Microbiome

Proteomes

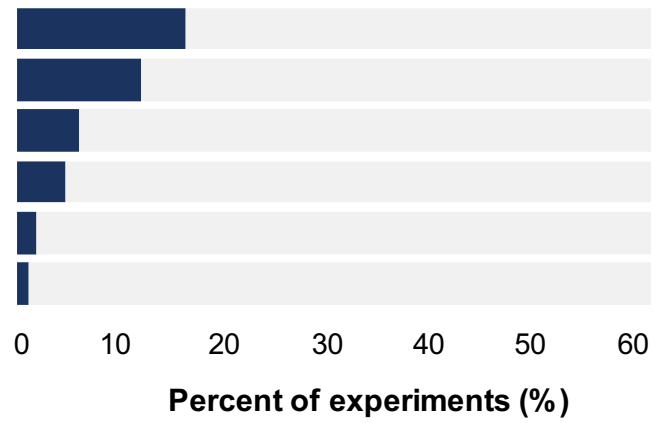

Percent of experiments (\%)

that perturbations in photosystem II often underlie the breakdown of the coral-dinoflagellate symbiosis (e.g., Iglesias-Prieto et al. 1993). However, measurements of reduced Fv/Fm alone are not sufficient to reveal photosynthetic dysfunction (e.g., Middlebrook et al. 2010), cannot be used as a substitute for direct photosynthesis measurements (Hoegh-Guldberg and Jones 1999; Lesser and Gorbunov 2001; Warner et al. 2010), and therefore cannot be reliably used as an indicator of bleaching severity. This is an important factor to consider moving forward, especially as $11 \%$ of heat-stress experiments that measured photosynthetic capacity using PAM did not measure any type of bleaching phenotype trait.

\section{Holobiont phenotype}

Unlike bleaching phenotype or photosynthetic capacity traits, holobiont phenotype traits include the physiological responses of the coral host. Thirty-nine percent of studies did not measure any aspect of the holobiont phenotype (Fig. 6). Of those that did, the most frequently measured traits were skeletal growth $(21 \%)$, energy reserves $(17 \%)$, and respiration (17\%) (Fig. 5c; Table S6.4.c). In terms of coral energy reserves, $13 \%$ of studies quantified soluble protein, $9 \%$ lipids, and $6 \%$ carbohydrates. However, most studies only measured a single holobiont trait, thus under representing the contribution of the host in the coral physiological response to heat-stress. When investigating 


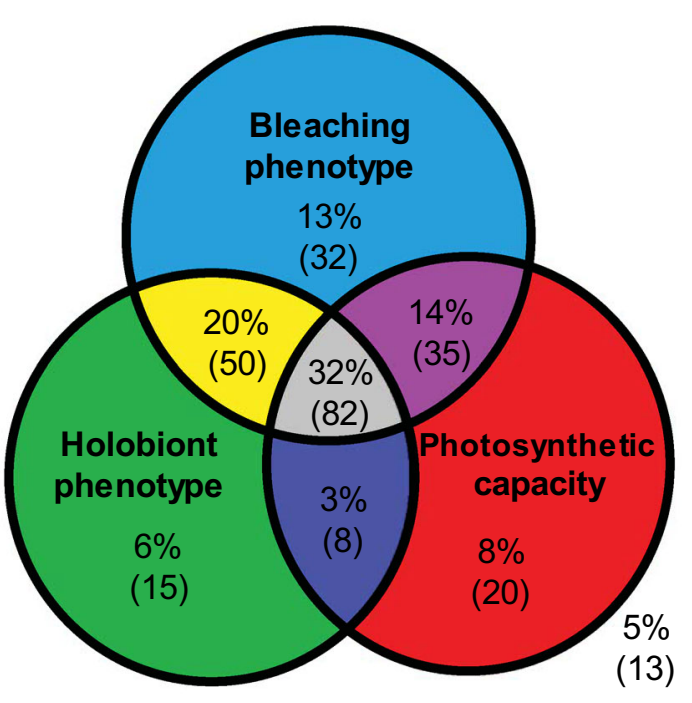

Fig. 6 Overlap in coral response variables measured in coral heatstress experiments between 1992 and April 2019 included in this review. Illustrated in the Venn diagram above are the percentage (and number of studies in parentheses) of experiments that measured at least one response variable within each trait category. For example, the purple section illustrates that $14 \%$ of experiments measured at least one photosynthetic capacity trait and at least one bleaching phenotype trait. Details regarding which coral response variables are within each trait category can be found in Table 1.3.4.a-c

the response of corals to heat-stress, it is important to measure a variety of holobiont traits as there is evidence that corals undergo physiological trade-offs to survive stressful environments. For example, it has been demonstrated that Acropora millepora harboring the thermotolerant Symbiodiniaceae Durusdinium, suffered concomitant decreases in lipid reserves and had smaller gamete size compared with colonies harboring the less thermotolerant Cladocopium (Jones and Berkelmen 2011). Similarly, under repeat-bleaching scenarios, Orbicella faveolata shifts toward Durisdinium dominance but concurrently undergoes declines in Symbiodiniaceae density, energy reserves, and calcification (Grottoli et al. 2014).

\section{Symbiodiniaceae identification}

Only $22 \%$ of experiments identified the species of Symbiodiniaceae harbored by their corals (Fig. 5d, Table S6.4.d). Knowing the identity of the dinoflagellate endosymbionts is important for bleaching studies because some Symbiodiniaceae species are more thermally tolerant than others. For example, corals that associate with $\mathrm{Du}$ rusdinium trenchii (formerly known as Symbiodinium clade D1a, LaJeunesse et al. 2018) are more resistant to bleaching than corals without this species of endosymbiont (Glynn et al. 2001; Berkelmans and van Oppen 2006). A small proportion of corals can also shuffle their dinoflagellate endosymbionts to harbor more thermotolerant species as an acclimation response to heat-stress (Buddemeier and Fautin 1993; Baker 2001, 2003; Berkelmans and van Oppen 2006; Jones et al. 2008; Grottoli et al. 2014). Yet, increased thermotolerance can come at a cost of reduced carbon translocation (Cantin et al. 2009), altered energetics (Jones and Berkelmans 2011, 2012), and reduced skeletal growth (Little et al. 2004; Jones and Berkelmans 2010; Grottoli et al. 2014; Cunning et al. 2015). Thus, if the endosymbiotic dinoflagellate community composition harbored by corals in an experiment is unknown, it makes distinguishing between environmental and genetic (Symbiodiniaceae species harbored) effects more challenging and reduces the reliability of inter-study comparisons. Taxonomic or functional profiles of other coral-associated microbes under heat-stress have been increasing in recent years with improvements in sequencing technologies, but are similarly understudied overall (only 10 of the 255 studies) (Fig. 5e).

\section{Summary}

Our results highlight substantial variability in the coral species studied during heat-stress experiments, the locations of those experiments, and the way in which they have been designed. In addition, we have identified a serious problem regarding the underreporting of critical methodological information. Data compiled under Goal 1 revealed that very little research has been conducted on the response of early life stage corals to heat stress. Similarly, a plethora of coral species and reefs locations have yet to be studied in heat-stress experiments. By quantifying the variability in coral heat-stress experiments under Goal 2, we identified two research areas that would benefit from increased congruence: standardization of experimental conditions (i.e., temperature level and ramp rate, light, flow, feeding regime, number of genets) and the length of acclimation and healing periods. In addition, the effects of prolonged experimental heat-stress $(>7 \mathrm{~d})$ is relatively understudied. Finally, data gathered under Goal 3 revealed that greater consistency in the number and type of response variables measured (within the three main categories: bleaching phenotype, holobiont phenotype, and photosynthetic capacity traits) are needed to better characterize coral responses to heat stress and provide a more holistic approach to our understanding of coral bleaching. Similarly, more consistent normalization methods or inclusion of multiple standardizations (e.g., chlorophyll concentration per $\mathrm{cm}^{2}$ and per gram dry weight) will further enable better comparisons among studies. Overall, understanding the specific ways in which heat-stress experiments are designed and executed is key to applying the results to corals on the reef. For instance, the results of a short-term, 
rapid temperature ramp experiment provide insight into the physiological responses of corals to short-term perturbations such as extreme low tides in lagoons (e.g., Oliver and Palumbi, 2011), whereas a long-term, gradual heat-stress onset design provides insight into the physiological responses of corals to natural bleaching events (e.g., Grottoli et al. 2014). Overall, this study provides the first comprehensive assessment of the methods and approaches used in coral heat-stress experiments and provides the foundation for developing best practice recommendations.

Acknowledgements We thank Bailey L., Dixon S., Lannon S., Moran M., Nainiger B., Noggle Y., O'Flynn E., and Ryan K. for assistance during data collection. We also thank the participants of the Coral Bleaching Research Coordination Network 2019 workshop for additional guidance and organizational support in completing this review. RM and JP were graduate students and SS an undergraduate student in the Grottoli lab during the execution of this work. This research was funded by the National Science Foundation (Award Number 1838667).

\section{Compliance with ethical standards}

Conflict of interest On behalf of all authors, the corresponding author states that there is no conflict of interest.

Open Access This article is licensed under a Creative Commons Attribution 4.0 International License, which permits use, sharing, adaptation, distribution and reproduction in any medium or format, as long as you give appropriate credit to the original author(s) and the source, provide a link to the Creative Commons licence, and indicate if changes were made. The images or other third party material in this article are included in the article's Creative Commons licence, unless indicated otherwise in a credit line to the material. If material is not included in the article's Creative Commons licence and your intended use is not permitted by statutory regulation or exceeds the permitted use, you will need to obtain permission directly from the copyright holder. To view a copy of this licence, visit http://creativecommons. org/licenses/by/4.0/.

\section{References}

Angilletta Jr (2009) Thermal Adaptation: A theoretical and empirical Synthesis. Oxford University Press, Oxford, UK

Anthony KRN (1999) Coral suspension feeding on fine particulate matter. J Exp Mar Bio Ecol 232:85-106

Anthony KRN, Connolly SR, Hoegh-Guldberg O (2007) Bleaching, energetics, and coral mortality risk: effects of temperature, light, and sediment regime. LimnolOceanogr 52:716-726

Anthony KRN, Fabricius KE (2000) Shifting roles of heterotrophy and autotrophy in coral energetics under varying turbidity. J Exp Mar Bio Ecol 252:221-253

Babcock RC, Bull GD, Harrison PL, Heyward AJ, Oliver JK, Wallace CC, Willis BL (1986) Synchronous spawnings of 105 scleractinian coral species on the Great Barrier Reef. Mar Biol 90:379-394

Baker AC (2001) Reef corals bleach to survive change. Nature 411:765-766
Baker AC (2003) Flexibility and specificity in coral-algal symbiosis: diversity, ecology, and biogeography of Symbiodinium. Annu Rev EcolEvol Syst 34:661-689

Baumann JH, Grottoli AG, Hughes AD, Matsui Y (2014) Photoautotrophic and heterotrophic carbon in bleached and non-bleached coral lipid acquisition and storage. J Exp Mar Bio Ecol 461:469-478

Baums IB, Baker AC, Davies SW, Grottoli AG, Kenkel CD, Kitchen SA, Kuffner IB, LaJeunesse TC, Matz M, Miller MW, Parkinson JE, Shantz AA (2019) Considerations for maximizing the adaptive potential of restored coral populations in the western Atlantic. Ecol Appl 29:e01978

Berkelmans R, van Oppen MJH (2006) The role of zooxanthellae in the thermal tolerance of corals: a "nugget of hope" for coral reefs in an era of climate change. Proc Biol Sci 273:2305-2312

Borneman E (2008) Introduction to the husbandry of corals in aquariums: a review. In: Leewis RJ, Janse M (eds) Advances in coral husbandry in public aquariums. Public aquarium husbandry series. Burgers's Zoo, Arnhem, the Netherlands, pp 3-14

Brown BE (1997) Coral bleaching: causes and consequences. Coral Reefs 16:S129-S138

Buddemeier RW, Fautin DG (1993) Coral bleaching as an adaptive mechanism: a testable hypothesis. Bioscience 43:320-327

Buddemeier RW, Kleypas JA, Aronson RB (2004) Coral reefs \& climate change: potential contributions of climate change to stresses on coral reef ecosystems. Pew Center for Climate Change, Arlington, VA

Cacciapaglia CW, van Woesik R (2015) Reef-coral refugia in a rapidly changing ocean. Glob Chang Biol 21:2272-2282

Cantin NE, Cohen AL, Karnauskas KB, Tarrant AM, McCorkle DC (2010) Ocean warming slows coral growth in the central Red Sea. Science 329:322-325

Cantin NE, van Oppen MJH, Willis BL, Mieog JC, Negri AP (2009) Juvenile corals can acquire more carbon from high-performance algal symbionts. Coral Reefs 28:405-414

Clarke KR, Gorley RN (2006) PRIMER v6: User Manual/Tutorial. PRIMER-E Ltd, Plymouth, UK

Craggs J, Guest JR, Davis M, Simmons J, Dashti E, Swet M (2017) Inducing broadcast coral spawning ex situ: Closed system mesocosm design and husbandry protocol. EcolEvol 7:11066-11078

Cumbo VR, Fan TY, Edmunds PJ (2013) Effects of exposure duration on the response of Pocillopora damicornis larvae to elevated temperature and high $p \mathrm{CO}_{2}$. J Exp Mar Bio Ecol 439:100-107

Cunning R, Gillette P, Capo T, Galvez K, Baker AC (2015) Growth tradeoffs associated with thermotolerant symbionts in the coral Pocillopora damicornis are lost in warmer oceans. Coral Reefs 34:155-160

Cziesielski MJ, Schmidt-Roach S, Aranda M (2019) The past, present, and future of coral heat stress studies. EcolEvol 9:10055-10066

D'Angelo C, Denzel A, Vogt A, Matz M, Oswald F, Salih A, Nienhaus GU, Wiedenmann J (2008) Blue light regulation of host pigment in reef-building corals. Mar Ecol Prog Ser 364:97-106

Dennison WC, Barnes DJ (1988) Effect of water motion on coral photosynthesis and calcification. J Exp Mar Bio Ecol 115:67-77

Dubinsky Z, Falkowski PG, Porter JW, Muscatine L (1984) Absorption and utilization of radiant energy by light-and shadeadapted colonies of the hermatypic coral Stylophora pistillata. Proc R Soc 214:203-214

Eakin CM, Lough JM, Heron SF, Stednick JD (2009) Climate variability and change: monitoring data and evidence for increased coral bleaching stress. In: van Oppen $\mathrm{MJH}$, Lough JM (eds) Coral bleaching - patterns, causes, and consequences. Springer-Verlag, Berlin, Heidelberg, pp 41-67 
Eakin CM, Sweatman HPA, Brainard RE (2019) The 2014-2017 global-scale coral bleaching event: insights and impacts. Coral Reefs 38:539-545

Edmunds PJ, Gates RD, Gleason DF (2001) The biology of larvae from the reef coral Porites astreoides, and their response to temperature disturbances. Mar Bio 139:981-989

Edmunds PJ, Gates R (2002) Normalizing physiological data for scleractinian corals. Coral reefs 21:193-197

Edmunds PJ, Spencer Davies P (1986) An energy budget for Porites porites (Scleractinia). Mar Biol 92:339-347

Falkowski PG, Dubinsky Z, Muscatine L, Porter JW (1984) Light and the bioenergetics of a symbiotic coral. Bioscience 34:705-709

Ferrier-Pagès C, Rottier CC, Beraud E, Levy O (2010) Experimental assessment of the feeding effort of three scleractinian coral species during a thermal stress: effect on the rates of photosynthesis. J Exp Mar Bio Ecol 390:118-124

Frieler K, Meinshausen M, Golly A, Mengel M, Lebek K, Donner SD, Hoegh-Guldberg $\mathrm{O}$ (2013) Limiting global warming to $2^{\circ} \mathrm{C}$ is unlikely to save most coral reefs. Nat Clim Chang 3:165-170

Glynn PW (1996) Coral reef bleaching: facts, hypotheses and implications. Glob Chang Biol 2:495-509

Glynn PW, Maté JL, Baker AC, Calderón MO (2001) Coral bleaching and mortality in Panama and Ecuador during the 1997-1998 El Niño - Southern Oscillation event: spatial/temporal patterns and comparisons with the 1982-1983 event. Bull Mar Sci 69:79-109

Grottoli AG, Rodrigues LJ, Palardy JE (2006) Heterotrophic plasticity and resilience in bleached corals. Nature 440:1186-1189

Grottoli AG, Warner ME, Levas SJ, Aschaffenburg MD, Schoepf V, Mcginley M, Baumann JH, Matsui Y (2014) The cumulative impact of annual coral bleaching can turn some coral species winners into losers. Glob Chang Biol 20:3823-3833

Grottoli AG, Toonen RJ, van Woesik R, Vega Thurber R, Warner M, McLachlan RH, Price JT, Bahr K, Baums I, Castillo KD, Coffroth MA, Cunning R, Dobson KL, Donahue M, Hench J, Iglesias-Prieto R, Kemp D, Kenkel C, Kline D, Kuffner I, Matthews J, Mayfield AB, Padilla-Gamino JL, Palumbi S, Voolstra C, Weis V, Wu H (2020) Increasing comparability among coral bleaching experiments. Ecol Appl e2262. https:// doi.org/10.1002/eap.2262

Grover R, Maguer JF, Allemand D, Ferrier-Pagès C (2008) Uptake of dissolved free amino acids by the scleractinian coral Stylophora pistillata. J Exp Biol 211:860-865

Harrison HB, Álvarez-Noriega M, Baird AH, Heron SF, MacDonald C, Hughes TP (2019) Back-to-back coral bleaching events on isolated atolls in the Coral Sea. Coral Reefs 38:713-719

Head CEI, Bayley DTI, Rowlands G, Roche RC, Tickler DM, Rogers AD, Koldewey H, Turner JR, Andradi-Brown DA (2019) Coral bleaching impacts from back-to-back 2015-2016 thermal anomalies in the remote central Indian Ocean. Coral Reefs 38:605-618

Hoegh-Guldberg O (1999) Climate change, coral bleaching and the future of the world's coral reefs. Mar Freshw Res 50:839-866

Hoegh-Guldberg O, Jones RJ (1999) Photoinhibition and photoprotection in symbiotic dinoflagellates from reef-building corals. Mar Ecol Prog Ser 183:73-86

van Hooidonk R, Maynard JA, Manzello D, Planes S (2014) Opposite latitudinal gradients in projected ocean acidification and bleaching impacts on coral reefs. Glob Chang Biol 20:103-112

van Hooidonk R, Maynard JA, Planes S (2013) Temporary refugia for coral reefs in a warming world. Nat Clim Chang 3:508-511

Houlbrèque F, Ferrier-Pagès C (2009) Heterotrophy in tropical scleractinian corals. Biol Rev 84:1-17

Hughes AD, Grottoli AG (2013) Heterotrophic compensation: a possible mechanism for resilience of coral reefs to global warming or a sign of prolonged stress? PLoS One 8:1-10
Hughes AD, Grottoli AG, Pease TK, Matsui Y (2010) Acquisition and assimilation of carbon in non-bleached and bleached corals. Mar Ecol Prog Ser 420:91-101

Hughes TP, Anderson KD, Connolly SR, Heron SF, Kerry JT, Lough JM, Baird AH, Baum JK, Berumen ML, Bridge TC, Claar DC, Eakin CM, Gilmour JP, Graham NAJ, Harrison HB, Hobbs JPA, Hoey AS, Hoogenboom MO, Lowe RJ, McCulloch MT, Pandolfi JM, Pratchett M, Schoepf V, Torda G, Wilson SK (2018a) Spatial and temporal patterns of mass bleaching of corals in the Anthropocene. Science 359:80-83

Hughes TP, Barnes ML, Bellwood DR, Cinner JE, Cumming GS, Jackson JBC, Kleypas J, van de Leemput IA, Lough JM, Morrison TH, Palumbi SR, van Nes EH, Scheffer M (2017) Coral reefs in the Anthropocene. Nature 546:82-90

Hughes TP, Kerry JT, Baird AH, Connolly SR, Dietzel A, Eakin CM, Heron SF, Hoey AS, Hoogenboom MO, Liu G, McWilliam MJ, Pears RJ, Pratchett MS, Skirving WJ, Stella JS, Torda G (2018b) Global warming transforms coral reef assemblages. Nature 556:492-496

Hughes TP, Kerry JT, Connolly SR, Baird AH, Eakin CM, Heron SF, Hoey AS, Hoogenboom MO, Jacobson M, Liu G, Pratchett MS, Skirving W, Torda G (2019) Ecological memory modifies the cumulative impact of recurrent climate extremes. Nat Clim Chang 9:40-43

Iglesias-Prieto R, Govind NS, Trench RK (1993) Isolation and characterization of three membrane-bound chlorophyll-protein complexes from four dinoflagellate species. Philos Trans R Soc London Ser B Biol Sci 340:381-392

IPCC (2013) Summary for Policy Makers. In: Stocker TF, Qin D, Plattner GK, Tignor M, Allen SK, Boschung J, Nauels A, Xia Y, Bex V, Midgley PM (eds) Climate change 2013: the physical science basis. Contribution of Working Group I to the Fifth Assessment Report of the Intergovernmental Panel on Climate Change. Cambridge University Press, Cambridge, United Kingdom and New York, NY, USA

Johnston EC, Forsman ZH, Toonen RJ (2018) A simple molecular technique for distinguishing species reveals frequent misidentification of Hawaiian corals in the genus Pocillopora. PeerJ 6:e4355

Jokiel PL, Coles SL (1990) Response to Hawaiian and other IndoPacific reef corals to elevated seawater temperature. Coral Reefs 8:155-162

Jokiel PL, Coles SL (1977) Effects of temperature on the mortality and growth of Hawaiian reef corals. Mar Biol 43:201-208

Jones AM, Berkelmans R (2010) Potential costs of acclimatization to a warmer climate: growth of a reef coral with heat tolerant vs. sensitive symbiont types. PLoS ONE 5:e10437

Jones AM, Berkelmans R (2011) Tradeoffs to thermal acclimation: energetics and reproduction of a reef coral with heat tolerant Symbiodinium type-D. J Mar Biol 2011:1-12

Jones AM, Berkelmans R (2012) The photokinetics of thermotolerance in Symbiodinium. Mar Ecol 33:490-498

Jones AM, Berkelmans R, van Oppen MJH, Mieog JC, Sinclair W (2008) A community change in the algal endosymbionts of a scleractinian coral following a natural bleaching event: field evidence of acclimatization. Proc R Soc B Biol Sci 275:1359-1365

Khalesi MK, Beeftink HH, Wijffels RH (2009) Light-dependency of growth and secondary metabolite production in the captive zooxanthellate soft coral Sinularia flexibilis. Mar Biotechnol 11:488-494

Kirk NL, Howells EJ, Abrego D, Burt JA, Meyer E (2018) Genomic and transcriptomic signals of thermal tolerance in heat-tolerant corals (Platygyra daedalea) of the Arabian/Persian Gulf. Mol Ecol 27:5180-5194 
LaJeunesse TC, Parkinson JE, Gabrielson PW, Jeong HJ, Reimer JD, Voolstra CR, Santos SR (2018) Systematic revision of Symbiodiniaceae highlights the antiquity and diversity of coral endosymbionts. Curr Biol 28:2570-2580.e6

Leal MC, Ferrier-Pagès C, Petersen D, Osinga R, Ferrier-Pagès C, Petersen D, Osinga R (2017) Corals. In: Calado R, Olivotto I, Oliver MP, Holt GJ (eds) Marine ornamental species aquaculture. Wiley, New York, pp 406-436

Lesser MP, Gorbunov MY (2001) Diurnal and bathymetric changes in chlorophyll fluorescence yields of reef corals measured in situ with a fast repetition rate fluorometer. Mar Ecol Prog Ser 212:69-77

Lesser MP, Stochaj WR, Tapley DW, Shick JM (1990) Bleaching in coral reef anthozoans: effects of irradiance, ultraviolet radiation, and temperature on the activities of protective enzymes against active oxygen. Coral Reefs 8:225-232

Levas SJ, Grottoli AG, Hughes AD, Osburn CL, Matsui Y (2013) Physiological and biogeochemical traits of bleaching and recovery in the mounding species of coral Porites lobata: implications for resilience in mounding corals. PLoS One $8: 32-35$

Lirman D (2000) Lesion regeneration in the branching coral Acropora palmata: effects of colonization, colony size, lesion size, and lesion shape. Mar Ecol Prog Ser 197:209-215

Little AF, van Oppen MJH, Willis BL (2004) Flexibility in algal endosymbioses shapes growth in reef corals. Science 304:1492-1494

Loya Y, Sakai K, Nakano Y, van Woesik R (2001) Coral bleaching: the winners and the losers. Ecol Lett 4:122-131

Marsh JA (1970) Primary productivity of reef-building calcareous red algae. Ecology 51:255-263

Marshall DJ, Morgan SG (2011) Ecological and evolutionary consequences of linked life-history stages in the sea. Curr Biol 21:R718-R725

Maynard J, van Hooidonk R, Eakin CM, Puotinen M, Garren M, Williams G, Heron SF, Lamb J, Weil E, Willis B, Harvell CD (2015) Projections of climate conditions that increase coral disease susceptibility and pathogen abundance and virulence. Nat Clim Chang 5:688-694

McClanahan TR, Maina J, Baker AC (2005) Effects of geography, taxa, water flow, and temperature variation on coral bleaching intensity in Mauritius. Mar Ecol Prog Ser 298:131-142

Middlebrook R, Anthony KRN, Hoegh-Guldberg O, Dove S (2010) Heating rate and symbiont productivity are key factors determining thermal stress in the reef-building coral Acropora formosa. J Exp Biol 213:1026-1034

Montgomery AD, Fenner D, Toonen RJ (2019) Annotated checklist for stony corals of American Samoa with reference to mesophotic depth records. Zookeys 849:1-170

Muller EM, Bartels E, Baums IB (2018) Bleaching causes loss of disease resistance within the threatened coral species Acropora cervicornis. Elife7:e35066:1-20

Nakamura T, van Woesik R (2001) Water-flow rates and passive diffusion partially explain differential survival of corals during the 1998 bleaching event. Mar Ecol Prog Ser 212:301-304

Nakamura T, Yamasaki H, van Woesik R (2003) Water flow facilitates recovery from bleaching in the coral Stylophora pistillata. Mar Ecol Prog Ser 256:287-291

Naumann MS, Niggl W, Laforsch C, Glaser C, Wild C (2009) Coral surface area quantification-evaluation of established techniques by comparison with computer tomography. Coral Reefs 28:109-117

Oliver T, Palumbi S (2011) Do fluctuating temperature environments elevate coral thermal tolerance? Coral Reefs 30:429-440
Omori M, Fukami H, Kobinata H, Hatta M (2001) Significant drop of fertilization of Acropora corals in 1999: an after-effect of heavy coral bleaching? LimnolOceanogr 46:704-706

Osinga R, Janssen M, Janse M (2008) The role of light in coral physiology and its implications of coral husbandry. In: Leewis RJ, Janse M (eds) Advances in coral husbandry in public aquariums. Burgers's Zoo, Arnhem, pp 173-183

Ow YX, Todd PA (2010) Light-induced morphological plasticity in the scleractinian coral Goniastrea pectinata and its functional significance. Coral Reefs 29:797-808

Palardy JE, Rodrigues LJ, Grottoli AG (2008) The importance of zooplankton to the daily metabolic carbon requirements of healthy and bleached corals at two depths. J Exp Mar Bio Ecol 367:180-188

Palumbi SR, Barshis DJ, Traylor-Knowles N, Bay RA (2014) Mechanisms of reef coral resistance to future climate change. Science 344:895-898

Petersen D (2008) The role of sexual coral reproduction in captive population management - a review. In: Leewis RJ, Janse M (eds) Advances in coral husbandry in public aquariums. Burgers' Zoo, Arnhem, the Netherlands, pp 319-323

Petersen D, Falcato J, Gilles P, Jones RJ (2007) Sexual reproduction of scleractinian corals in public aquariums: current status and future perspectives. Int Zoo Yearb 41:122-137

Putnam HM, Gates RD (2015) Preconditioning in the reef-building coral Pocillopora damicornis and the potential for trans-generational acclimatization in coral larvae under future climate change conditions. J Exp Biol 218:2365-2372

R Core Development Team (2017) R: a language and environment for statistical computing. R Foundation for Statistical Computing, Vienna, Austria

Reynaud S, Ferrier-Pagès C, Boisson F, Allemand D, Fairbanks RG (2004) Effect of light and temperature on calcification and strontium uptake in the scleractinian coral Acropora verweyi. Mar Ecol Prog Ser 279:105-112

Richmond RH, Hunter CL (1990) Reproduction and recruitment of corals: comparisons among the Caribbean, the Tropical Pacific, and the Red Sea. Mar Ecol Prog Ser 60:185-203

Ritson-Williams R, Arnold SN, Fogarty ND, Steneck RS, Vermeij MJA, Paul VJ (2009) New perspectives on ecological mechanisms affecting coral recruitment on reefs. Smithson Contrib Mar Sci 38:437-457

Ritson-Williams R, Ross C, Paul VJ (2016) Elevated temperature and allelopathy impact coral recruitment. PLoS One 11:e0166581

Rodrigues LJ, Grottoli AG (2006) Calcification rate and the stable carbon, oxygen, and nitrogen isotopes in the skeleton, host tissue, and zooxanthellae of bleached and recovering Hawaiian corals. GeochimCosmochim Acta 70:2781-2789

Rodrigues LJ, Grottoli AG, Lesser MP (2008) Long-term changes in the chlorophyll fluorescence of bleached and recovering corals from Hawaii. J Exp Biol 211:2502-2509

Rosado PM, Leite DCA, Duarte GAS, Chaloub RM, Jospin G, Nunes da Rocha U, Saraiva JP, Dini-Andreote F, Eisen JA, Bourne DG, Peixoto RS (2019) Marine probiotics: increasing coral resistance to bleaching through microbiome manipulation. ISME J 13:921-936

Ross C, Ritson-Williams R, Olsen K, Paul VJ (2013) Short-term and latent post-settlement effects associated with elevated temperature and oxidative stress on larvae from the coral Porites astreoides. Coral Reefs 32:71-79

Scheufen T, Krämer WE, Iglesias-Prieto R, Enríquez S (2017) Seasonal variation modulates coral sensibility to heat-stress and explains annual changes in coral productivity. Sci Rep 7:1-15

Schoepf V, Grottoli AG, Warner ME, Cai WJ, Melman TF, Hoadley KD, Pettay DT, Hu X, Li Q, Xu H, Wang Y, Matsui Y, Baumann 
JH (2013) Coral energy reserves and calcification in a high-CO2 world at two temperatures. PLoS One 8:e75049

Stimson JS, Kinzie RA (1991) The temporal pattern and rate of release of zooxanthellae from the reef coral Pocillopora damicornis (Linnaeus) under nitrogen-enrichment and control conditions. J Exp Mar Bio Ecol 153:63-74

Strong AE, Arzayus F, Skirving W, Heron SF (2006) Identifying coral bleaching remotely via Coral Reef Watch - improved integration and implications for changing climate. In: Phinney JT (ed) Coastal and estuarine studies. American Geophysical Union, Washington, DC, pp 163-180

Szmant AM (1986) Reproductive ecology of Caribbean reef corals. Coral Reefs 5:43-53

Thurber RV, Willner-Hall D, Rodriguez-Mueller B, Desnues C, Edwards RA, Angly FE, Dinsdale E, Kelly L, Rohwer F (2009) Metagenomic analysis of stressed coral holobionts. Environ Microbiol 11:2148-2163

UNEP-WCMC (2018) Global Coral Disease Database. https://www. unep-wcmc.org/resources-and-data/global-coral-diseasedatabase

Veron JEN, Hoegh-Guldberg O, Lenton TM, Lough JM, Obura DO, Pearce-Kelly P, Sheppard CRC, Spalding M, Stafford-Smith
MG, Rogers AD (2009) The coral reef crisis: the critical importance of $<350 \mathrm{ppm}$ CO2. Mar Pollut Bull 58:1428-1436

Warner ME, Lesser MP, Ralph PJ (2010) Chlorophyll fluorescence in reef building corals. In: Suggett DJ (ed) Chlorophyll a fluorescence in aquatic sciences: methods and applications. Springer, Netherlands, Dordrecht, pp 209-222

Wiedenmann J, D'Angelo C, Smith EG, Hunt AN, Legiret FE, Postle AD, Achterberg EP (2013) Nutrient enrichment can increase the susceptibility of reef corals to bleaching. Nat Clim Chang 3:160-164

Wijgerde T, van Melis A, Silva CIF, Leal MC, Vogels L, Mutter C, Osinga R (2014) Red light represses the photophysiology of the scleractinian coral Stylophora pistillata. PLoS One 9:1-10

Wilkinson C (2000) The 1997-98 mass coral bleaching and mortality event: 2 years on. In: Wilkinson C (ed) Status of coral reefs of the World: 2000. Australian Institute of Marine Science, Townsville, Australia, pp 21-34

Publisher's Note Springer Nature remains neutral with regard to jurisdictional claims in published maps and institutional affiliations. 